\title{
LUPUS PATIENTS INFECTED BY SARS-COV2 PERFORMED LESS SOCIAL ISOLATION WITH HIGHER HOSPITALIZATION ASSOCIATED WITH HYPERTENSION AND CYCLOPHOSPHAMIDE PULSOTHERAPY - DATA FROM REUMACOV BRAZIL
}

Joana Starling de Carvalho ${ }^{1, \star}$, Edgard Torres dos Reis Neto², Adriana Maria Kakehasi ${ }^{1}$, Odirlei André Monticielo ${ }^{3}$, Sandra Lúcia Euzébio Ribeiro ${ }^{4}$, Cleandro Pires de Albuquerque ${ }^{5}$, Samia Araujo de Sousa Studart ${ }^{6}$, Gustavo Flores Chapacais ${ }^{3}$, Lilian David de Azevedo Valadares ${ }^{7}$, Henrique Ataide Mariz ${ }^{7}$, Flavia Patrícia Sena Teixeira Santos ${ }^{1}$, Adriana Oliveira Marinho ${ }^{8}$, Nafice Costa Araújo ${ }^{9}$, Samuel Katsuyuki Shinjo ${ }^{10}$, Francinne Machado Ribeiro ${ }^{11}$, Ana Carolina Oliveira e Silva Montandon ${ }^{12}$, Thiago Rached da Silva ${ }^{13}$, Danielle Christinne Soares Egypto de Brito ${ }^{14}$, Silviane Vassalo ${ }^{15}$, Claudia Diniz Lopes Marques ${ }^{7}$, Ana Paula Monteiro Gomides $^{16}$, Eduardo dos Santos Paiva ${ }^{17}$, Gecilmara Cristina Salviato Pileggi ${ }^{10}$, Licia Maria Henrique da Mota ${ }^{5}$, Marcelo Medeiros Pinheiro², Ricardo Machado Xavier ${ }^{3}$, Gilda Aparecida Ferreira ${ }^{1}$

1.Universidade Federal de Minas Gerais, Belo Horizonte (MG), Brazil; 2.Universidade Federal de São Paulo, São Paulo (SP), Brazil; 3.Universidade Federal do Rio Grande do Sul, Porto Alegre (RS), Brazil; 4.Universidade Federal do Amazonas, Manaus (AM), Brazil; 5.Universidade de Brasília, Brasília (DF), Brazil;6.Hospital Geral de Fortaleza, Fortaleza (CE), Brazil; 7.Universidade Federal de Pernambuco, Recife (PE), Brazil; 8.Fundação Hospital Estadual do Acre, Rio Branco (AC), Brazil; 9.Instituto de Assistência Médica ao Servidor Público Estadual, São Paulo (SP), Brazil; 10.Universidade de São Paulo, São Paulo (SP), Brazil; 11.Universidade do Estado do Rio de Janeiro, Rio de Janeiro (RJ), Brazil; 12.Universidade Federal de Goiás, Goiânia (GO), Brazil; 13.Instituto de Medicina Integral Professor Fernando Figueira, Recife (PE), Brazil; 14.Universidade Federal da Paraíba, João Pessoa (PB), Brazil; 15.Universidade Federal de Juiz de Fora, Juiz de Fora (MG), Brazil; 16.Centro Universitário de Brasília, Brasília (DF), Brazil; 17.Universidade Federal do Paraná, Curitiba (PR), Brazil.

*Corresponding author: joanastarling@yahoo.com.br

\section{BACKGROUND}

Systemic lupus erythematosus (SLE) patients have infections more frequent with higher morbidity and mortality when compared to the general population. To date, few studies have described the impact of SARS-CoV-2 infection, specifically in SLE patients. In addition to questions regarding COVID-19 incidence and outcomes in SLE patients, it is not known whether the infection could induce disease flare. The objective was to evaluate factors associated with COVID-19 severity outcomes in SLE patients.

\section{METHODS}

The ReumaCoV-Brasil is a multicenter, prospective cohort to monitor rheumatic diseases patients during SARS-CoV-2 pandemic. SLE adult patients with a diagnosis of COVID-19 were compared to those without COVID-19. SLE activity was evaluated by the patient global assessment (PGA) and SLE disease activity index (SLEDAI 2k).

\section{RESULTS}

A total of 604 SLE patients were included, 317 (52.4\%) with COVID-19 and 287 (47.6\%) in the control group. COVID-19 SLE patients reported a lower frequency of social isolation and worked more frequently as health professionals presented more frequently joint ( $32.5 \%$ vs. $22.0 \% ; p=0.004)$ and hematological manifestations ( $18.0 \%$ vs. $11.5 \% ; p=0.025)$. There was no difference in the mean SLEDAI-2K score between both groups in the post-COVID-19 period (5.8 [8.6] vs. 4.5 [8.0]; $p=0.190$ ). However, infected patients report feeling worse about SLE activity at this period (PGA:2.9 [2.9] vs. 2.3 [2.6]; $p=0.031$ ). In the univariate logistic regression analysis, the presence of two or more comorbidities, prednisone (or equivalent) $>20 \mathrm{mg} /$ day, pulse therapy with methylprednisolone or cyclophosphamide were associated with severe COVID-19. Systemic arterial hypertension (OR: 2.48 [1.04-5.91], $p=0.041$ ) and cyclophosphamide pulse therapy (OR: 14.32 [2.12-96.77], $p=0.006$ ) were independently associated with a greater chance of hospitalization related to COVID-19. Patients who received telemedicine support presented 67\% less chance of hospitalization (OR: 0.33 [0.12-0.88], $p=0.02$ ).

\section{CONCLUSION}

Hypertension and cyclophosphamide were associated with severity outcome and telemedicine can be a useful tool for SLE patients with COVID-19.

\section{KEYWORDS}

Systemic lupus erythematosus, SARS-CoV-2, COVID-19, Hospitalization. 